\title{
Risco de Câncer em Pacientes que Vivem com HIV/Aids: Revisão Sistemática
}

doi: https://doi.org/10.32635/2176-9745.RBC.2020v66n4.1053

\author{
Cancer Risk in Patients Living with HIV/AIDS: Systematic Review \\ Riesgo de Cáncer en Pacientes que Viven con VIH/Sida: Revisión Sistemática
} Larissa Di Leo Nogueira Costa ${ }^{1}$; Aline Santos Kennelly ${ }^{2}$; Dayse Azevedo Coelho de Souza ${ }^{3}$; Uiara Regina Silva de Lima ${ }^{4}$; Conceição de
Maria Pedrozo Silva de Azevedo

\section{RESUMO}

Introduçáo: O câncer acometerá cerca de 50\% dos indivíduos com infecção pelo vírus da imunodeficiência adquirida (HIV), com importante carga daqueles do tipo não definidores da síndrome da imunodeficiência adquirida (aids). Objetivo: Analisar diferentes fatores de risco para câncer do tipo não definidor na população HIV positiva, por meio da seleção de estudos de coorte realizados em diferentes Regiōes do mundo. Método: Trata-se de uma revisão de literatura realizada no período de março a abril de 2019, utilizando os descritores Cancer Risck, HIV e non-AIDS-defining Cancer. Resultados: Os cânceres não definidores, que representam maior incidência entre a população HIV positiva, são o de pulmão, colorretal, cervical, de vagina e útero, gástrico, linfoma de Hodgkin e de fígado. Conclusáo: Os estudos demonstram risco aumentado para diversos tipos de câncer não definidores da aids, o que nos leva a um novo paradigma, voltado náo somente para o controle do HIV, mas também para a detecção precoce e tratamento oportuno, a fim de minimizar as morbidades e aumentar a expectativa de vida desses indivíduos.

Palavras-chave: Neoplasias; Infecçôes por HIV/complicações; Sobreviventes de Longo Prazo ao HIV; Revisão Sistemática.

\section{ABSTRACT}

Introduction: Cancer will affect about $50 \%$ of HIV (human immunodeficiency virus) infected individuals with a significant burden of non-AIDS-defining cancers (acquired immunodeficiency syndrome). Objective: To analyse different risk factors for the non-defining type in the HIV positive population through selection of cohort studies conducted in several regions of the world. Method: Literature review conducted from March to April 2019 using the descriptors Cancer Risk, HIV and nonAIDS-defining Cancer. Results: Non-defining cancers representing the greatest incidence among HIV-positive population are lung, colorectal, cervical, vaginal and uterine, gastric, Hodgkin's lymphoma, and liver. Conclusion: Studies demonstrate that there are increased risks for several types of non-AIDS defining cancers, leading to a new paradigm, not only for HIV control but for early detection and timely treatment, in order to minimize the morbidities and increase life expectancy of these individuals. Key words: Neoplasms; HIV Infections/complications; HIV Long-Term Survivors; Systematic Review.

\section{RESUMEN}

Introducción: El cáncer afectará aproximadamente al 50\% de las personas con infección por virus de inmunodeficiencia adquirida (VIH) con una carga significativa de cánceres que no definen el síndrome de inmunodeficiencia adquirida (sida). Objetivo: Analizar diferentes factores de riesgo para el cáncer no definitorio en la población VIH positivo en estudios de cohortes realizados en diferentes regiones del mundo. Método: Esta es una revisión de la literatura realizada de marzo a abril de 2019 utilizando los descriptores Cancer Risk, HIV non-AIDS-defining Cancer. Resultados: Los cánceres no definitorios que representan el mayor riesgo e incidencia entre la población VIH positivo son de pulmón, colorrectal, cervical, vaginal y uterino, gástrico, linfoma de Hodgkin y de hígado. Conclusión: Los estudios muestran riesgos para varios tipos de cáncer que no definen el sida, lo que nos lleva a un nuevo paradigma, que se centra no solo en el control del VIH sino también en la detección temprana y el tratamiento oportuno.

Palabras clave: Neoplasias; Infecciones por VIH/complicaciones; Sobrevivientes de VIH a Largo Plazo; Revisión Sistemática.

'Universidade Federal do Maranhão (UFMA). São Luís (MA), Brasil. OrcidiD:http://orcid.org/0000-0003-3206-612X

${ }^{2}$ UFMA. São Luís (MA), Brasil. OrcidiD:http://orcid.org/0000-0002-1943-1404

3UFMA. São Luís (MA), Brasil. OrcidiD:http://orcid.org/0000-0002-24251459

${ }^{4}$ UFMA. São Luís (MA), Brasil. OrcidiD:http://orcid.org/0000-0002-0021-7184

5UFMA. São Luís (MA), Brasil. OrcidiD:http://orcid.org/0000-0003-0712-1852

Endereço para correspondência: Larissa Di Leo Nogueira Costa. UFMA. Avenida dos portugueses, 1966 - Vila Bacanga. São Luís (MA), Brasil. CEP 65065-545.

E-mail: conceicaopedrozo@gmail.com 


\section{INTRODUÇÃO}

O câncer acometerá cerca de 50\% dos indivíduos com infecção pelo vírus da imunodeficiência adquirida (HIV), sendo uma parte considerável da carga da doença e da mortalidade da patologia atribuível ao vírus. Os cânceres do tipo definidores da infecção marcam o início da imunossupressão clinicamente relevante e surgem por meio da perda do controle imunológico de infecçôes virais oncogênicas, muito comuns principalmente antes da introdução da terapia antirretroviral. Entre eles, os mais comuns são o sarcoma de Kaposi, linfoma não Hodgkin e câncer do colo do útero ${ }^{1}$.

A introdução da Highly Active Antiretroviral Therapy (HAART), conhecida também como terapia antirretroviral combinada, trouxe um controle da carga viral a níveis muito baixos e recuperação das taxas de células CD4+ e CD8+, modificando o panorama epidemiológico da população portadora de HIV e promovendo um aumento da expectativa de vida ${ }^{2}$.

$\mathrm{O}$ aumento da longevidade foi um ganho para pessoas que vivem com o HIV, porém, com o decorrer dos anos, observou-se que esse aumento na expectativa de vida promoveu também um aumento na exposição cumulativa à inflamação sistêmica e acúmulo de mutações somáticas, bem como alterações epigenéticas relacionadas à carcinogênese, elevando a incidência de neoplasias não relacionadas à síndrome da imunodeficiência adquirida (aids), como os cânceres anal, de fígado e pulmáo $\mathrm{o}^{2,3}$.

Alguns fatores podem estar envolvidos a um maior risco de câncer na população infectada pelo HIV, tais como: a) aumento de novos casos da doença; b) taxas mais altas de tabagismo na população; c) aumento da imunossenescência; d) replicação viral residual abaixo de níveis detectáveis; e) infecção por vírus oncogênicos: papilomavírus humano (HPV), Epstein-Barr, hepatite B (HBV) e hepatite $\mathrm{C}(\mathrm{HCV})$, que podem se multiplicar em virtude do quadro de imunodepressão $0^{3,4}$.

Dessa forma, esta revisão tem por objetivo analisar diferentes fatores de risco para cânceres do tipo não definidor na populaçáo HIV positiva, em estudos de coorte realizados em diferentes Regiōes do mundo.

\section{MÉTODO}

A presente revisão sistemática foi realizada de acordo com a estratégia Preferred reporting Items for Systematic Reviews and Meta-analyses (PRISMA) para a lista de verificação e construção do fluxograma em quatro etapas principais (identificação, seleção, elegibilidade e inclusão). A revisão atual foi cadastrada no International Prospective Register of Systematic Reviews (PROSPERO) com número de registro CRD42020168929.
A elaboração da questão de pesquisa foi fundamentada na estratégia PICO, com "P" referindo-se à população do estudo (pessoas que vivem com HIV); "I" à intervençâo estudada ou à variável de interesse (fator de risco); "C" à comparação com outra variável (pessoas sem o HIV); "O" referente ao desfecho de interesse (desenvolvimento de câncer). Dessa forma, definiu-se a pergunta norteadora para a condução da presente pesquisa: "Quais neoplasias têm maior risco de incidência em pessoas soropositivas?"

Foi realizada uma busca, no período de março a abril de 2019, considerando artigos de todos os anos sem recorte temporal específico, pelo motor de busca PubMed, principal ferramenta de recuperação de dados da Medical Literature Analysis and Retrievel System Online (MEDLINE). Os descritores controlados utilizados para esta pesquisa foram Cancer Risck, HIV and Cancer nonAIDS-defining, pesquisados separadamente e de forma combinada.

Os critérios de inclusão para a seleção dos artigos foram: a) presença dos descritores selecionados; b) artigos de texto completo disponíveis na Internet; c) publicaçóes em português, inglês ou espanhol; d) estudos com definiçôes metodológicas sistematizadas e coerentes. Foram excluídos estudos descritivos que não forneceram método utilizado e/ou resultados obtidos, bem como artigos incompletos, revisões e editoriais.

Estudos duplicados foram identificados e excluídos para realização da leitura do resumo trabalhos selecionados. Aqueles incluídos após essa etapa foram submetidos à análise crítica focada no método utilizado, resultados obtidos e Regiōes de realização das pesquisas.

A estratégia de síntese dos dados incluiu a identificação, a seleção, a elegibilidade e a inclusão. A pesquisa na base de dados resultou em 260 artigos no total, excluindo-se 73 revisóes. Realizou-se leitura minuciosa dos títulos e resumos de 187 trabalhos, pela qual se constatou que 169 deles não se enquadravam nos critérios de elegibilidade desta pesquisa, resultando em 11 artigos que compóem o corpus desta revisão, como se pode observar no fluxograma de pesquisa dos artigos (Figura 1).

Com o objetivo de minimizar possível viés de aferição dos estudos, como erros de interpretação e delineamento, dois pesquisadores realizaram a leitura dos artigos e preencheram os instrumentos separadamente para posterior comparativo. Nos casos em que ocorreram divergências, aplicou-se nova leitura com preenchimento do instrumento por um terceiro pesquisador independente.

\section{RESULTADOS}

Nesta revisão, foi aplicado o sistema de classificação composto de sete níveis: a) nível I (evidências oriundas 


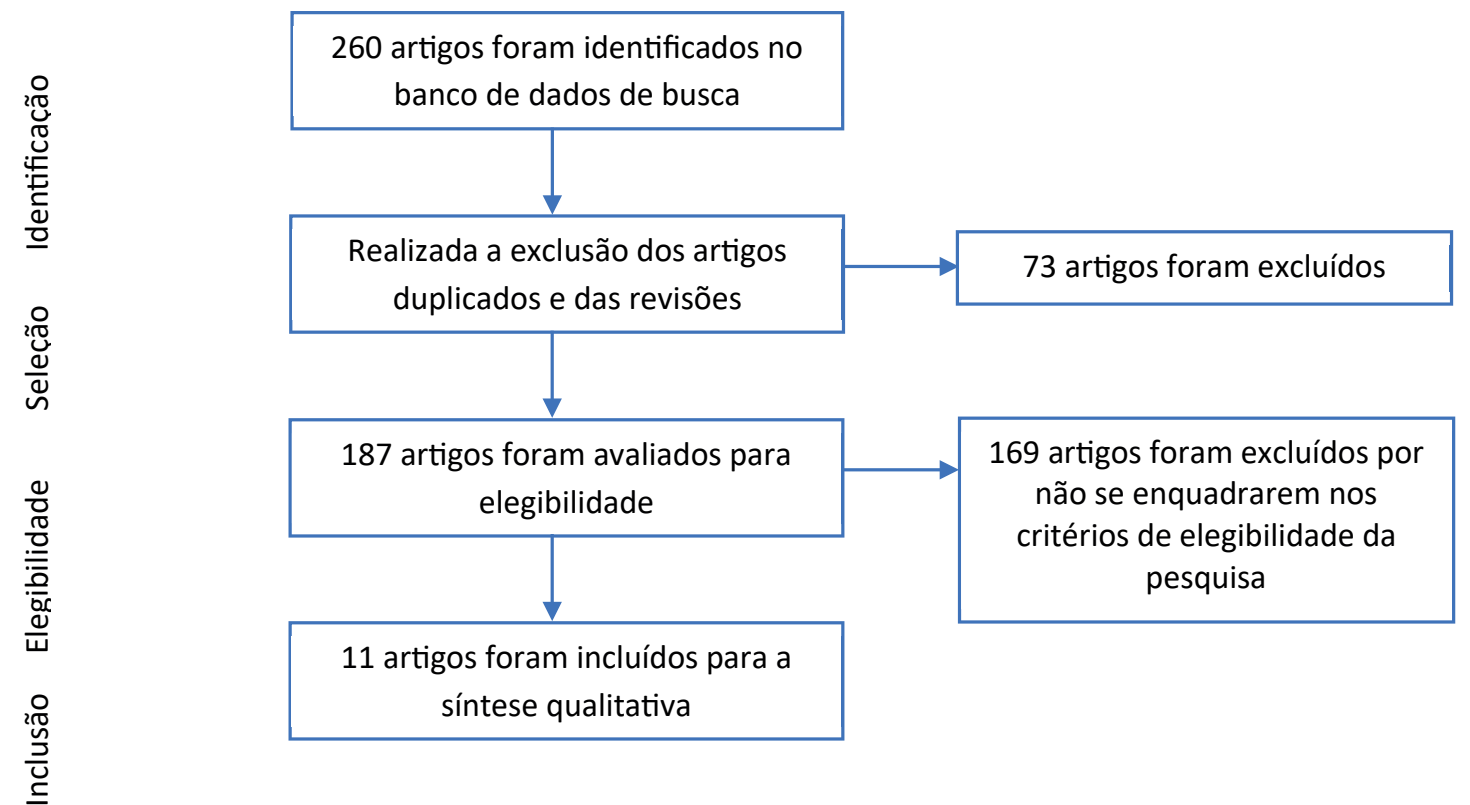

Figura 1. Fluxograma de pesquisa dos artigos

de revisôes sistemáticas ou metanálise de relevantes ensaios clínicos); b) nível II (evidências derivadas de pelo menos um ensaio clínico randomizado, controlado, bem delineado); c) nível III (ensaios clínicos bem delineados, sem randomização); d) nível IV (estudos de coorte e de caso-controle bem delineados); e) nível V (revisão sistemática de estudos descritivos e qualitativos); f) nível VI (evidências derivadas de um único estudo descritivo ou qualitativo); g) nível VII (opiniāo de autoridades ou relatório de comitês de especialistas). Todos os artigos incluídos na pesquisa foram classificados com nível de evidência IV.
Os estudos selecionados foram de coortes, realizados em oito países diferentes: Espanha, França, Itália, Inglaterra, Japão, Estados Unidos da América (EUA), México e Brasil. Abrangendo os continentes da Europa, América e Ásia. Pode-se observar a distribuição geográfica das pesquisas incluídas neste estudo na Figura 2.

Entre os países citados, os cânceres que apresentaram maior incidência na populaçáo que vive com HIV em relação à população sem a infecção foram de pulmão, colorretal, cervical, de vagina e útero, gástrico, linfoma de Hodgkin e de fígado. Os artigos levantados estão descritos na Tabela 1 .

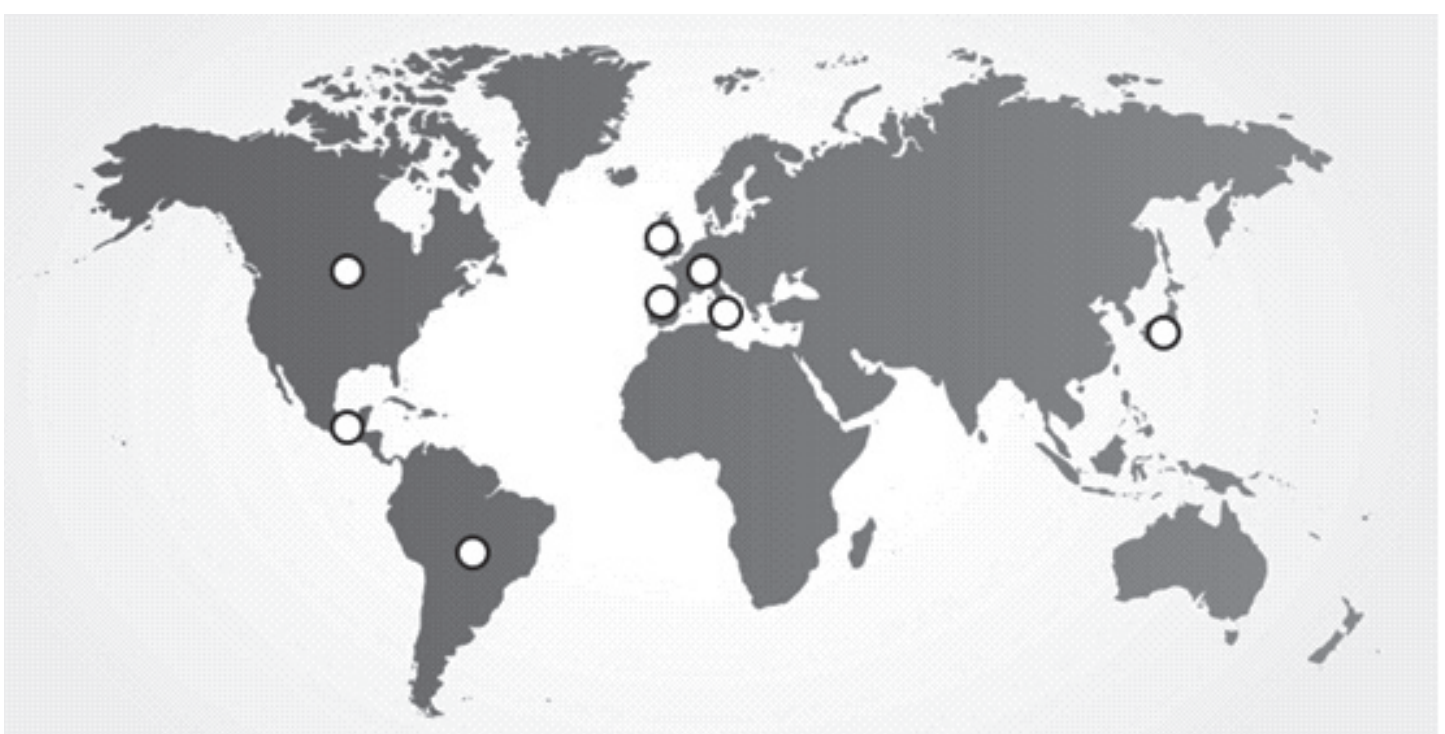

Figura 2. Representação gráfica da distribuição dos países onde foram realizadas as coortes 
Tabela 1. Resultados apresentados pelos artigos selecionados

\begin{tabular}{|c|c|c|c|c|}
\hline Título & País & $\mathbf{N}$ & Ano & Resultados \\
\hline $\begin{array}{l}\text { Riesgo de cáncer en personas } \\
\text { con VIH en España, 2004-2015. } \\
\text { Estudio de la cohorte CoRIS }\end{array}$ & Espanha & 12.239 & 2019 & $\begin{array}{l}\text { Os cânceres não definidores que } \\
\text { apresentaram maior risco foram linfoma de } \\
\text { Hodgkin, colo do útero, mama e cabeça e } \\
\text { pescoço em mulheres }\end{array}$ \\
\hline $\begin{array}{l}\text { Risk for cancer among people } \\
\text { living with AIDS, 1997-2012: the } \\
\text { São Paulo AIDS - cancer linkage } \\
\text { study }\end{array}$ & $\begin{array}{l}\text { São Paulo - } \\
\text { Brasil }\end{array}$ & 87.109 & 2018 & $\begin{array}{l}\text { Os maiores riscos em homens foram os } \\
\text { cânceres anal e linfoma de Hodgkin e, } \\
\text { nas mulheres, os riscos foram aumentados } \\
\text { para cânceres de fígado, anal, de amídala, } \\
\text { orofaringe, nasofaringe, vulva e vagina }\end{array}$ \\
\hline $\begin{array}{l}\text { Increased risk of non-AIDS- } \\
\text { defining cancers in Asian HIV- } \\
\text { infected patients: a long-term } \\
\text { cohort study }\end{array}$ & $\begin{array}{l}\text { Tóquio - } \\
\text { Japão }\end{array}$ & 1.118 & 2018 & $\begin{array}{l}\text { Os cânceres não definidores que } \\
\text { apresentaram um risco marcadamente } \\
\text { aumentado foram de fígado, colo do útero } \\
\text { e estômago }\end{array}$ \\
\hline $\begin{array}{l}\text { Non-AIDS defining cancer } \\
\text { (NADC) among HIV-infected } \\
\text { patients at an oncology tertiary- } \\
\text { care center in Mexico }\end{array}$ & México & 127 & 2018 & $\begin{array}{l}\text { Em homens, os cânceres que apresentaram } \\
\text { maior risco de desenvolvimento foram } \\
\text { linfoma de Hodgkin, seguido de } \\
\text { câncer anal, enquanto, em mulheres, } \\
\text { vulvovaginal, seguido de mama }\end{array}$ \\
\hline $\begin{array}{l}\text { Risk of non-AIDS-defining } \\
\text { cancers among HIV-1-infected } \\
\text { individuals in France between } \\
1997 \text { and 2009: results from a } \\
\text { French cohort }\end{array}$ & França & 84.504 & 2014 & $\begin{array}{l}\text { Os cânceres que apresentaram maior risco } \\
\text { foram de pulmão, linfoma de Hodgkin, } \\
\text { anal e fígado }\end{array}$ \\
\hline $\begin{array}{l}\text { Trends and predictors of non- } \\
\text { AIDS-defining cancers in men } \\
\text { and women with HIV infection: } \\
\text { a single-institution retrospective } \\
\text { study before and after the } \\
\text { introduction of HAART }\end{array}$ & $\begin{array}{l}\text { Milão - } \\
\text { Itália }\end{array}$ & 5.924 & 2013 & $\begin{array}{l}\text { Nas mulheres, os cânceres que } \\
\text { apresentaram maior risco de ocorrência } \\
\text { foram de vulva, linfoma de Hodgkin, anal } \\
\text { e de pulmão. Nos homens, os riscos foram } \\
\text { para câncer anal; linfoma de Hodgkin, de } \\
\text { amígdala, pulmão e fígado }\end{array}$ \\
\hline $\begin{array}{l}\text { HIV infection and the risk of } \\
\text { cancers with and without a } \\
\text { known infectious cause }\end{array}$ & $\begin{array}{l}\text { Califórnia - } \\
\text { EUA }\end{array}$ & 20.277 & 2009 & $\begin{array}{l}\text { De forma geral, os cânceres com maior } \\
\text { risco para a população HIV foram de } \\
\text { células escamosas anal e linfoma de } \\
\text { Hodgkin }\end{array}$ \\
\hline $\begin{array}{l}\text { Cancer risk in people infected } \\
\text { with human immunodeficiency } \\
\text { virus in the United States }\end{array}$ & EUA & 57.350 & 2008 & $\begin{array}{l}\text { Entre os cânceres não definidores de aids, } \\
\text { foi observada incidência elevada de câncer } \\
\text { de pulmão, linfoma de Hodgkin e câncer } \\
\text { da cavidade oral/faringe, ânus, laringe, } \\
\text { fígado, pâncreas e pênis }\end{array}$ \\
\hline $\begin{array}{l}\text { The risk of cancer in HIV-infected } \\
\text { people in southeast England: a } \\
\text { cohort study }\end{array}$ & Inglaterra & 26.080 & 2005 & $\begin{array}{l}\text { Os cânceres mais incidentes em homens } \\
\text { foram: ânus e canal anal, fígado, } \\
\text { brônquios e pulmão, outras células, } \\
\text { sarcoma de Kaposi, nervos e tecidos } \\
\text { moles, linfonodo secundário, outros locais } \\
\text { secundários, local desconhecido, doença de } \\
\text { Hodgkin, linfoma não Hodgkin, leucemias } \\
\text { e outros hematopoiéticos linfoides }\end{array}$ \\
\hline $\begin{array}{l}\text { Risk of cancer in persons with } \\
\text { AIDS in Italy, 1985-1998 }\end{array}$ & Itália & 12.104 & 2003 & $\begin{array}{l}\text { Os cânceres que apresentaram maior risco } \\
\text { de ocorrência foram o de ânus, pulmão, } \\
\text { cérebro, doença de Hodgkin e leucemias }\end{array}$ \\
\hline $\begin{array}{l}\text { Risk of cancer in patients with } \\
\text { HIV disease. London African } \\
\text { HIV/AIDS Study Group }\end{array}$ & Inglaterra & 2.048 & 1999 & $\begin{array}{l}\text { Os cânceres não definidores da aids mais } \\
\text { comuns foram a doença de Hodgkin e } \\
\text { cancro anal }\end{array}$ \\
\hline
\end{tabular}




\section{DISCUSSÃO}

A Organização Mundial da Saúde 5 (OMS) estima que, em 2018, houve cerca de 17 milhóes de novos casos de câncer em todo o mundo, entre a população total, com cerca de 9,5 milhóes de mortes por doenças neoplásicas. Em geral, os tipos mais incidentes foram os cânceres de pulmão, mama, colorretal, próstata, estômago, pulmão, esôfago e cervical, sendo estes também os principais tipos com as maiores mortalidades.

Em pesquisa realizada por nove anos, com 1.185 pacientes adultos portadores de HIV no Japão, 49,2\% das pessoas que foram diagnosticadas com câncer não definidor já apresentavam estágio avançado do tumor e idade média de 57 anos. Metade dos casos de neoplasias não definidoras da aids foi de câncer gástrico. Observou-se aumento significativo da incidência de câncer de fígado e reto em população soropositiva quando comparada à população geral ${ }^{6}$.

Os países asiáticos possuem os maiores números de incidência e mortalidade por câncer entre a populaçáo geral do mundo. Estão concentrados nesse continente $50,9 \%$ da incidência e $57,4 \%$ da mortalidade por câncer no mundo, levando a uma estimativa de 8,6 milhóes de novos casos no ano de $2018^{5}$.

Tanto na população japonesa geral quanto na população portadora do HIV, há uma forte incidência do câncer gástrico. Segundo Nagata et al. ${ }^{6}$, no Japão, há uma elevada prevalência do $H$. pylori associado à maior ocorrência da condição pré-cancerosa de metaplasia intestinal, o que traz grandes riscos do câncer gástrico à população geral e, quando associado à diminuição da imunidade, aumenta significativamente a exposição à infecçáo e à gastrite severa, levando ao aumento do risco de câncer gástrico especialmente em portadores do HIV.

Em trabalho estudo realizado na Espanha, com 12.239 pessoas portadores do HIV, que foram acompanhados em uma coorte por 11 anos, a média da idade dos participantes foi de 41 anos, dos quais, 61,8\% desenvolveram algum tipo de câncer não definidor. Em comparação com a população geral, o risco de câncer foi o dobro em homens com HIV. Entre os riscos relativos mais elevados encontrados no estudo, estão o linfoma de Hodgkin e o câncer de pulmão, em ambos os sexos; linfoma não Hodgkin maior em homens e câncer do colo do útero, cabeça e pescoço, entre as mulheres?

O câncer de pulmão é uma das causas mais importantes da morbimortalidade e o tipo de câncer mais prevalente entre os não definidores levantados em diversos estudos, como, por exemplo, nos realizados por García-Abellán et al. ${ }^{7}$, no qual $50 \%$ dos participantes eram tabagistas, o dobro da prevalência entre a população geral. Além disso, o potencial oncogênico do tabaco, em pessoas HIV positivas, pode ser prolongado por até cinco anos após a cessação do hábito de fumar, o que promove um grande risco para o câncer de pulmão nessa populaçãa ${ }^{7-9}$.

Uma pesquisa realizada na França avaliou 84.504 indivíduos com HIV, na qual a idade do diagnóstico de câncer foi significativamente mais jovem entre os indivíduos infectados pelo vírus para linfoma de Hodgkin e câncer de fígado, sendo 9 vezes maior para linfoma de Hodgkin e 2,4 vezes maior para câncer de fígado. $\mathrm{O}$ mesmo estudo indicou ainda que esse risco se aproximou do risco da população geral para câncer de pulmão ${ }^{10}$.

Dois estudos foram realizados na Itália, o primeiro envolvendo 4.382 homens e 1.542 mulheres com HIV demonstrou risco aumentado em ambos os sexos para os cânceres anal, linfoma de Hodgkin e de pulmão. Para as mulheres HIV positivas, o risco foi aumentado para câncer de vulva e, para os homens, de amígdala, pulmáo e de fígado?. O segundo também encontrou risco elevado para os cânceres de ânus, pulmão, linfoma de Hodgkin e, diferente do primeiro, identificou incidência de câncer de cérebro ${ }^{11}$.

Para Dal Maso et al. ${ }^{11}$, o câncer cerebral pode ter alta incidência por erros de interpretação durante o fechamento do seu diagnóstico. Massas de origem não neoplásicas ou massas atribuíveis ao linfoma não Hodgkin poderiam ter sido erroneamente diagnosticadas como tumores cerebrais, resultando em um risco alterado para esse tipo de neoplasia.

Em pesquisa realizada na Inglaterra, houve uma taxa de incidência padronizada significativamente aumentada para todos os cânceres não definidores de aids em homens, porém, não foi significativa em mulheres. Os principais tipos de neoplasia foram: câncer anal, fígado, brônquios e pulmão, nervos e tecidos moles, linfonodo secundário, linfoma de Hodgkin e leucemias. Apesar da grande variedade de tipos encontrados, foi também um dos estudos com maior número de participantes, com recrutamento de 26.080 homens e 7.110 mulheres $^{12}$.

Já para a pesquisa realizada por Petruckevitch et al. ${ }^{13}$, também na Inglaterra, os cânceres definidores foram os mais prevalentes e os náo definidores encontrados foram somente o linfoma de Hodgkin e câncer anal. Uma das possíveis causas de outros tipos com risco elevado na populaçáo HIV positiva não terem sido identificados é o período do estudo. A HAART teve maior adesão em 1996, somente, a partir de então, houve aumento da expectativa de vida do paciente com HIV e da cura da aids, levando ao aparecimento de outras doenças como outros tipos de neoplasias ${ }^{2}$.

A Europa está entre as maiores incidências de novos casos de câncer e de índices de mortalidade entre a 
população geral, 3,9 e 1,9 milhôes respectivamente, ficando atrás apenas dos países asiáticos. Os principais tipos de doenças neoplásicas que acometem a população europeia são câncer de próstata, pulmão, colorretal e bexiga nos homens; e mama, colorretal, pulmão e colo do útero nas mulheres ${ }^{5,14}$. Quando comparados, o câncer de próstata, bexiga e mama não foram observados com incidência significativa para a populaçáo HIV positiva.

Seguida da Europa, a América do Norte possui 1,8 milhão de novos casos de câncer entre a população geral, com 692 mil mortes em 20185. Em dois trabalhos distintos, realizados nos EUA, com pacientes portadores do HIV, houve uma alta incidência de linfoma de Hodgkin, câncer anal e câncer de pulmão. Engels et al. ${ }^{15}$ demonstraram risco significativamente elevado para os cânceres cervical, oral, de laringe, fígado, pâncreas e pênis ${ }^{8,15}$.

A América do Sul é a quarta Região com maior incidência de câncer entre a população geral do mundo, são cerca de 1,3 milhão de novos casos e 665 mil mortes estimadas no ano de 2018 ${ }^{5}$. Em um estudo de coorte realizado no Brasil, com populaçáo HIV positiva da cidade de São Paulo, o câncer não definidor colorretal foi o que apresentou maior risco. Estima-se que a infecção por HPV seja responsável por $93 \%$ de todos os casos de câncer anal de células escamosas. Em uma coorte realizada no Rio de Janeiro (Brasil), com 863 mulheres soropositivas, foi identificado que $51 \%$ tiveram infecção anal com HPV carcinogênico de alto risco e $31 \%$ apresentaram citologia anal anormal. Em uma coorte com 84.504 pacientes HIV positivos na França, houve um risco 79 vezes maior para ocorrência de câncer anal nessa população em comparação com a população total ${ }^{3,10,16}$.

Nas mulheres com HIV, os cânceres cervical e de vulva, vagina e útero foram os mais frequentes encontrados nos estudos. Esses cânceres estão associados a diferentes tipos de HPV e também a baixas coberturas de exames de rastreamento como o teste de Papanicolaou. No Brasil, as diretrizes nacionais recomendam a realização do exame preventivo anualmente na população entre 25 e 64 anos, porém são necessárias políticas públicas voltadas para a prevenção do HPV e o diagnóstico precoce, específicas para a população com HIV ${ }^{3,11}$.

Em pesquisa realizada no México com 1.126 indivíduos HIV positivos, $11 \%$ desenvolveram câncer não definidor, sendo $5 \%$ de neoplasias primárias múltiplas. Os cânceres não definidores mais incidentes foram o linfoma de Hodgkin e câncer anal em homens; e o câncer vulvovaginal e de mama nas mulheres ${ }^{17}$.

Os tumores associados a infecçôes virais representaram $50 \%$ de todas as neoplasias na pesquisa realizada por Cornejo-Juárez et al. ${ }^{17}$, com maior incidência do linfoma de Hodgkin, que está associado à infecção pelo vírus Epstein-Barr, e os cânceres colorretal, vulvar e vaginal. Em outro estudo, realizado na cidade da Califórnia, nos EUA, os cânceres relacionados a infecçóes representaram 70\%, com destaque também para o linfoma de Hodgkin e o câncer colorretal. Uma coorte, realizada na França, indicou um risco 26 vezes maior de ocorrência de linfoma de Hodgkin na população com HIV, mesmo em indivíduos com recuperaçáo celular de $\mathrm{CD} 4+^{8,10,17}$. Outros trabalhos sugerem que a reconstituiçáo imune induzida pela HAART pode aumentar o risco de linfoma de Hodgkin, ao ampliar a estimulação de células B e o quantitativo de linfócitos infectados pelo vírus Epstein-Barr?.

Franzetti et al. ${ }^{9}$ indicam que há um aumento significativo na contagem de CD4+ no momento do diagnóstico de câncer, ao comparar com o período de imunossupressáo, sugerindo que o $\mathrm{CD} 4$ baixo náo prediz a ocorrência de neoplasias e justificando o fato de muitas delas não diminuírem o seu risco com o aumento da contagem de CD4. Já em uma coorte realizada na Itália, os autores ${ }^{9}$ afirmam que a recuperação imunológica em pacientes com imunodeficiência grave pode não diminuir o risco de câncer não definidor, possivelmente porque não há uma recuperação completa, sugerindo que esses tipos de câncer não necessitam estar estritamente associados a um alto grau de imunossupressão no momento do seu diagnóstico ${ }^{9,17}$.

Nos trabalhos elencados, todos os cânceres do tipo definidores e a maioria dos cânceres não definidores ocorreram em taxas mais altas na população HIV positiva. As pesquisas também demonstraram que esses pacientes são acometidos por doenças neoplásicas geralmente em idades mais precoces do que a população geral. Os estudos demonstraram que todos os cânceres associados à infecção por HPV, com exceção dos de língua e pênis, tiveram taxas aumentadas na população HIV positiva, em comparação com a população geral.

\section{CONCLUSÃO}

O presente artigo demonstrou que os cânceres não definidores, que representam maior risco e incidência entre a populaçáo HIV positiva, são os de pulmão, colorretal, cervical, de vagina e útero, gástrico, linfoma de Hodgkin e de fígado. Apesar de o tumor cerebral ter se apresentado como câncer de risco para essa população, há divergências entre os estudos com relação à sua causa, podendo ser atribuída também a equívocos nos diagnósticos.

Os trabalhos aqui apresentados demonstraram um maior risco para diversos tipos de câncer na população soropositiva, acometendo em idades mais precoces quando comparada à população geral, o que nos traz a reflexấo sobre a necessidade de políticas específicas de prevenção e 
diagnóstico precoce, não somente sobre o câncer definidor de HIV, mas também de outros tipos de câncer.

A prevenção primária, incluindo estratégias para incentivar a cessação do tabagismo e reduzir o consumo de álcool, a vacinação contra vírus potencialmente oncogênicos, como HPV e HBV, e o tratamento eficaz de infecçóes crônicas, incluindo HAART, são ferramentas importantes no manejo do câncer entre pessoas infectadas pelo HIV. A detecção precoce do câncer por meio de triagem e tratamento oportuno poderia contribuir ainda mais para reduzir a morbimortalidade nessa população, além do aumento na qualidade de vida desses indivíduos.

Mesmo que o delineamento dos estudos selecionados tenha sido adequado à verificação do risco de câncer em pessoas que vivem com HIV, faz-se necessário o desenvolvimento de mais pesquisas para testar associaçóes de variáveis que possam estar envolvidas nesse processo. Ressaltam-se algumas limitaçóes, tais como a não inclusão de outros idiomas, a busca dos artigos ter sido realizada por um único pesquisador, apesar de a análise ter sido realizada por outros dois, e a realização da coleta feita em apenas uma base de dados.

Os resultados obtidos permitiram identificar lacunas do conhecimento, principalmente em relação à necessidade de avaliação da justificativa para um risco aumentado de determinadas patologias na população HIV positiva.

\section{CONTRIBUIÇÕES}

Larissa Di Leo Nogueira Costa contribuiu na concepção e planejamento do manuscrito; na obtenção, análise e interpretação dos dados; e na redação. Aline Santos Kennelly contribuiu na redação. Dayse Azevedo Coelho de Souza contribuiu na redação e revisão crítica com contribuição intelectual. Uiara Regina Silva de Lima contribuiu na concepção e no desenho do trabalho. Conceição de Maria Pedrozo Silva de Azevedo contribuiu na concepção e planejamento do manuscrito; na análise e interpretação dos dados; na redação e revisão crítica. Todas as autoras aprovaram a versão final a ser publicada.

\section{DECLARAÇÃO DE CONFLITO DE INTERESSES}

Nada a declarar.

\section{FONTES DE FINANCIAMENTO}

Não há.

\section{REFERÊNCIAS}

1. Shiels MS, Engels EA. Evolving epidemiology of HIVassociated malignancies. Current Opinion HIV/AIDS [Internet]. 2017[cited 2020 maio 15];12(1):6-11.
Available from: https://www.natap.org/2017/HIV/ Evolving_epidemiology_of_HIV_associated.pdf

2. Castillo-Mancilla JR, Brown T, Erlandson K. Suboptimal adherence to combination antiretroviral therapy is associated with higher levels of inflammation despite HIV suppression. Clin Infects Dis. 2016;63(12):1661-7. doi: https://doi.org/10.1093/cid/ciw650

3. Tanaka LF, Latorre MRDO, Gutierrez EB, et al. Risk for cancer among people living with AIDS, 1997-2012: the São Paulo AIDS - cancer linkage study. Eur J Cancer Prev. 2018;27(4):411-7. doi: https://doi.org/10.1097/ CEJ.0000000000000339

4. Mitsuyasu. Non-AIDS-defining cancers. Top Antivir Med. 2014;22(3):660-5.

5. World Health Organization; International Agency for Research on Cancer. All cancers excl. non-melanoma skin cancer [Internet]. Global Cancer Observatory; 2019 Mar [cited 2020 maio 15]. Available from: https://gco.iarc.fr/ today/data/factsheets/cancers/40-All-cancers-excludingnon-melanoma-skin-cancer-fact-sheet.pdf

6. Nagata N, Nishijima T, Niikura R, et al. Increased risk of non-AIDS-defining cancers in Asian HIV-infected patients: a long-term cohort study. BMC Cancer. 2018;18(1):1066. doi: https://doi.org/10.1186/s12885018-4963-8

7. García-Abellán J, Del Río L, García JA, et al. Riesgo de cáncer en personas con VIH en España, 2004-2015. Estudio de la cohorte CoRIS. Enferm Infecc Microbiol Clin. 2019;37(8):502-8. doi: https://doi.org/10.1016/j. eimc.2018.11.011

8. Silverberg MJ, Chao C, Leyden WA, et al. HIV infection and the risk of cancers with and without a known infectious cause. AIDS. 2009;23(17):2337-45. doi: https://doi.org/10.1097/QAD.0b013e3283319184

9. Franzetti M, Adorni F, Parravicini C, et al. Trends and predictors of non-AIDS-defining cancers in men and women with HIV infection: a singleinstitution retrospective study before and after the introduction of HAART. J Acquir Immune Defic Syndr. 2013;62(4):414-20. doi: https://doi.org/10.1097/ QAI.0b013e318282a189

10. Hleyhel M, Hleyhel M, Bouvier AM, et al. Risk of non-AIDS-defining cancers among HIV-1-infected individuals in France between 1997 and 2009: results from a French cohort. AIDS. 2014;28(14):2109-18. doi: https://doi.org/10.1097/QAD.0000000000000382

11. Dal Maso L, Franceschi S, Polesel J, et al. Risk of cancer in persons with AIDS in Italy, 1985-1998. Br J Cancer. 2003;89(1):94-100. doi: https://doi.org/10.1038/ sj.bjc. 6601017

12. Newnham A, Harris J, Evans HS, et al. The risk of cancer in HIV-infected people in southeast England: a cohort study. Br J Cancer. 2005;92(1):194-200. doi: https:// doi.org/10.1038/sj.bjc. 6602273 
13. Petruckevitch A, Del Amo J, Phillips AN, et al. Risk of cancer in patients with HIV disease. London African HIV/ AIDS Study Group. Int J STD AIDS. 1999;10(1):38-42. doi: https://doi.org/10.1258/0956462991913060

14. Ferlay J, Colombet M, Soerjomataram I, et al. Cancer incidence and mortality patterns in Europe: estimates for 40 countries and 25 major cancers in 2018. Eur J Cancer. 2018;103:356-87. doi: https://doi.org/10.1016/j. ejca.2018.07.005

15. Engels EA, Biggar RJ, Hall HI, et al. Cancer risk in people infected with human immunodeficiency virus in the United States. Int J Cancer. 2008;123(1):187-94. doi: https://doi.org/10.1002/ijc.23487

16. Cambou MC, Luz PM, Lake JE, et al. Anal human papillomavirus (HPV) prevalences and factors associated with abnormal anal cytology in HIV-infected women in an urban cohort from Rio de Janeiro, Brazil. AIDS Patient Care STDS. 2015;29(1):4-12. doi: https://doi. org/10.1089/apc.2014.0166

17. Cornejo-Juárez P, Cavildo-Jerónimo D, VolkowFernández P. Non-AIDS defining cancer (NADC) among HIV-infected patients at an oncology tertiary-care center in Mexico. AIDS Res Ther. 2018;15:16. doi: https://doi. org/10.1186/s12981-018-0202-2 